\title{
Influence of Hot Band Annealing and Cold Rolling on Texture and Ridging of 430 Stainless Steel Containing Aluminum
}

\author{
Sudipta Patra, Lokesh Kumar Singhal
}

Jindal Stainless Limited, Hisar, India.

Email: psudiptapatra@gmail.com

Received October $7^{\text {th }}, 2012$; revised November $4^{\text {th }}, 2012$; accepted December $2^{\text {nd }}, 2012$

\begin{abstract}
An approach to optimize the processing parameters to get superior ridging resistance and mechanical properties in commercial production of 430 ferritic stainless steel has been studied. Attention was also paid to improve productivity and energy saving without hampering the surface and mechanical property aspects of the material. Hot rolled coils annealed by slow cooling under insulated cover exhibit better ridging resistance than bell annealing treatment with a minor decrease in ductility. Soaking temperature prior to hot rolling has a significant effect on ridging resistance.
\end{abstract}

Keywords: Ridging; Hood Annealing; Bell Annealing; Microstructure; Texture; 430 Stainless Steel

\section{Introduction}

Ferritic stainless steel 430 grade is extensively used in various applications like kitchen wares, electrical appliances, automobile parts and white goods on account of its good corrosion resistance, high thermal conductivity and beautiful surface gloss as a low cost alternative to nickel containing austenitic stainless steel. Occurrence of ridging after cold forming operation can hamper the surface finish of the material necessitating considerable effort in polishing of the surface. Wright [1] has pointed out that ridging is associated with anisotropic plasticity of bands of contrasting textures. Shin et al. [2] established that differences in the deformation behavior of $\{001\}<110>$ and $\{111\}<110>$ grain colonies arises due to difference in their plastic strain ratio during cold forming operation thereby causing ridging. Extensive efforts have been made to minimize ridging. Kim et al. [3] suggested refinement of solidification structure by using EMS to avoid columnar grains with $<001>/ / N D$ orientation is utilized for improving ridging resistance. This entails significant capital cost. Kimura et al. [4] advocated high interpass time during roughing in conjunction with high reduction per pass to facilitate recrystallization in the colony structures. High interpass time during rough rolling can adversely affect the productivity of the hot mill. Since 430 stainless steel has two phase $\alpha$ $+\gamma$ structure during hot rolling, some martensite forms on cooling of the hot coils. Such coils are generally subjected to bell annealing to transform the martensite to ferrite to facilitate cold rolling. Jha et al. [5] concluded that continuously hot band annealed material exhibits superior roping characteristic. In this study, they also noticed that more than $25 \%$ martensite in the microstructure can cause breakage of the coil during cold rolling. Huh et al. [6] observed pronounced through thickness texture gradient in hot bands of this grade which had an impact on appearance of ridging in the final recrystallised sheet. Huh and Engler [7] suggested that introducetion of intermediate anneal during cold rolling weaken the texture gradients and minimize the extent of ridging compared to single stage cold rolled product. Avila \& Zapata [8] annealed the hot bands of 430 grade in 2 phase region and followed by controlled cooling to obtain dual phase structure. These authors noted that grain refinement due to martensite dispersion during cold rolling resulted in significant improvement in ridging. Mola et al. [9] found that samples without hot band annealing when subjected to cold rolling and subsequent bell annealing exhibited superior ridging resistance compared to conventional bell annealed product which was continuously annealed after cold reduction. Batch annealing is an energy intensive operation which increases cost of the finished product. The present paper highlights the beneficial use of the intrinsic heat of the hot rolled coil under an insulated hood to enable the coil to cool slowly and thereby facilitate transformation of austenite to ferrite and reduce the hardness of martensite to permit extensive cold reduction. In this manner 430 grade with superior 
ridging resistance has been successfully produced at a lower processing cost. The paper describes plant trials with different processing routes with variations in mode of annealing and amount of cold reduction. The study was done on coils made from continuously cast slabs through EAF-AOD-LF-CC route without using EMS. Mechanical properties, texture, ridging characteristics of product in inner and outer wrap as well as in the middle of the coils are presented.

\section{Experimental Detail}

The chemical composition of AISI 430 ferritic stainless steel used in the current study is shown in Table 1. Four Continuously casted slabs of $200 \mathrm{~mm}$ thickness were hot rolled in a roughing and steckel mill to $2.5 \mathrm{~mm}$ thick coil. Processing schedule of these four slabs is given in Figures 1(a)-(d). Coil-A was soaked at $1170^{\circ} \mathrm{C}$ and then hot rolled in roughing and finishing at steckle mill upto 2.5 $\mathrm{mm}$ thickness. The coil was cooled in air to room temperature and then bell annealed at $820^{\circ} \mathrm{C}$ for $8 \mathrm{hrs}$. Thereafter it was cold rolled to $0.6 \mathrm{~mm}$ and finally continuously annealed at $820^{\circ} \mathrm{C}$. Coil B was soaked at $1210^{\circ} \mathrm{C}$ and then it followed the same route of coil A, just to investigate the effect of soaking temperature. Coil $\mathrm{C}$ and $\mathrm{D}$ were kept in an insulated box just after hot rolling and allowed to cool slowly. Coil $\mathrm{C}$ was then directly cold rolled to $0.6 \mathrm{~mm}$ and finally continuous annealed at $820^{\circ} \mathrm{C}$. Coil D was subjected to $33 \%$ cold reduction and continuously annealed at $820^{\circ} \mathrm{C}$ and thereafter cold rolled to $0.6 \mathrm{~mm}$ and finally continuously annealed at $820^{\circ} \mathrm{C}$. Samples from the centre as well as end portions were cut from the coils for microstructural characterization and mechanical property evaluation. The specimens were etched chemically by glyceregia reagent to reveal the microstructural features in optical microscope. Microstructures were examined by Carl Zeiss optical microscope and Carl Zeiss EVO-40 scanning electron microscope. Micro-texture was studied by Zeiss EVO-40 SEM attached with Oxford Inca EBSD system and analysed with HKL software. Ridging characteristics were measured after giving $20 \%$ tensile elongation by instrument manufactured by Mitutoyo. Hardness was evaluated by Vickers hardness test under $10 \mathrm{~kg}$ load. Tensile testing was done in a universal testing machine and Ericsson cupping test was performed for investigating the stretchability of the sheets.

Table 1. Chemical composition of the steel used in this study.

\begin{tabular}{ccccccccc}
\hline $\mathrm{C} \%$ & $\mathrm{Mn} \%$ & $\mathrm{~S} \%$ & $\mathrm{P} \%$ & $\mathrm{Si} \%$ & $\mathrm{Ni} \%$ & $\mathrm{Cr} \%$ & $\mathrm{~N} \%$ & $\mathrm{Al} \%$ \\
0.06 & 0.6 & 0.004 & 0.03 & 0.4 & 0.1 & 16.1 & 0.032 & 0.05 \\
\hline
\end{tabular}

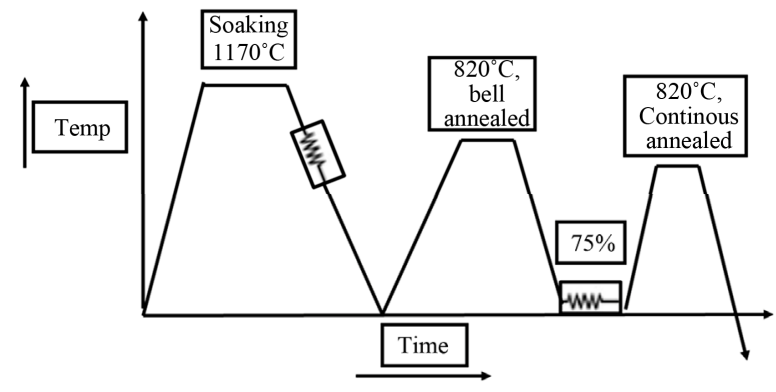

(a)

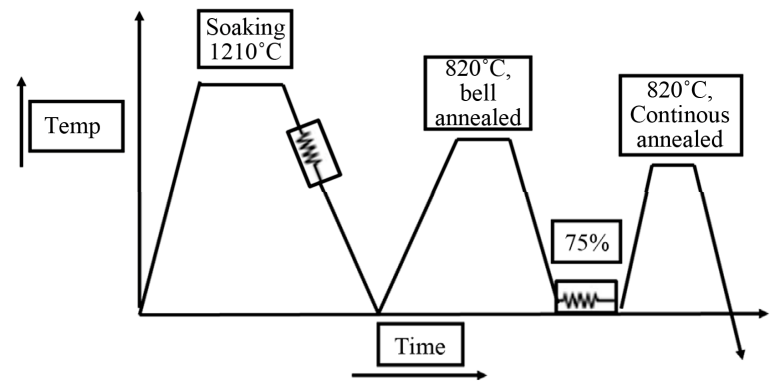

(b)

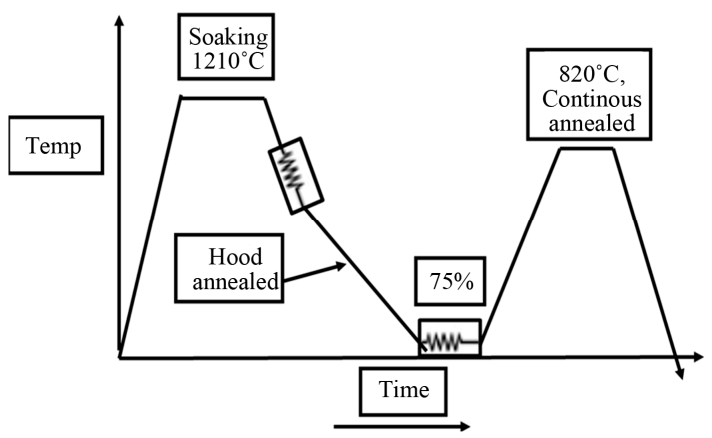

(c)

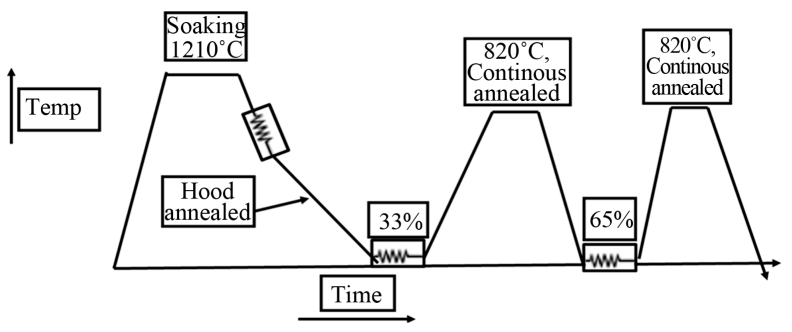

(d)

Figure 1. Processing route of four coils. (a) Coil A; (b) Coil B; (c) Coil C; (d) Coil D.

\section{Results and Discussion}

\subsection{Ridging Resistance}

Ridging height after $20 \%$ elongation under tension is shown in Figure 2. Ridging height is highest for Coil A and then it has decreased in coil B, C and D. In all cases coil end sample is showing higher ridging resistance than coil centre sample. As coil A and coil B had similar 
processing schedule and only difference is soaking temperature, better ridging resistance in coil B can be explained by the high soaking temperature. Hood annealed coils are showing better ridging resistance than bell annealed coils due to the randomization of initial texture by deformation in dual phase microstructure.

\subsection{Microstructure and Texture of Hot Bands}

Microstructure of as hot rolled coil B is shown in Figure 3. It contains approximately $35 \%$ martensite in ferrite. Microstructure of entire cross section of coil B after bell annealing is shown in Figure 4. Ferrite grains are finer

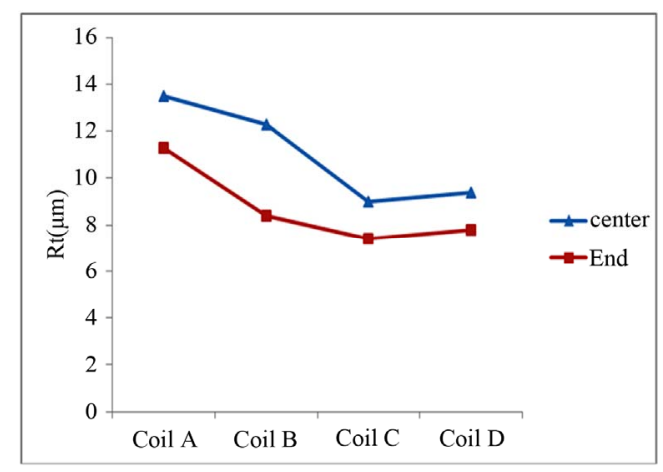

Figure 2. Roughness measurement of different coils after $20 \%$ tensile elongation.

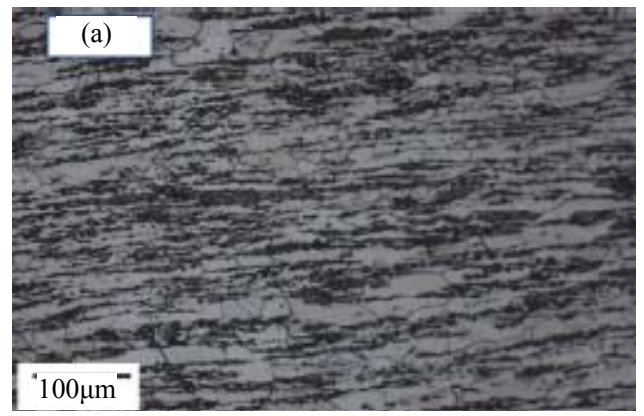

Figure 3. Cross section microstructure of as hot rolled coil B.

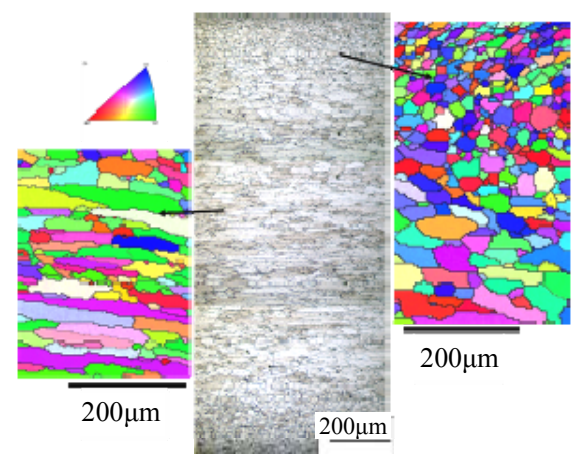

Figure 4. Collage of microstructure throughout the thickness coil B just after bell annealing along with Inverse pole figure map of subsurface and center region taken in RD. near surface and relatively coarser in the center. Interspersed carbide particles are also visible. Surface region consists of equiaxed grain of size of $30-35 \mu \mathrm{m}$ but center layer has elongated grains with $80-100 \mu \mathrm{m}$. The finer equiaxed grains constitute only 30 volume percent of the microstructure. Texture study revealed random texture in the subsurface layer and mostly $\alpha$ fiber component in the center region of the band. Wei et al. [10] studied the hot band annealing of a ferritic stainless steel and concluded that elongated ferrite grains with $\alpha$ fibre orientation had not recrystallized during bell annealing.

Microstructure of the coils C\&D after hood annealing exhibits banded structure with lamella of ferrite and tempered martensite (Figure 5(a)). Hardness after hood annealing decreased from nearly $200 \mathrm{HV}$ to $175 \mathrm{HV}$. Hood annealed coils could be given very heavy deformation without any breakage of the coil with beneficial effect on ridging resistance. Microstructure of coil D after $33 \%$ cold reduction followed by continuous annealing is shown in Figure 5(b).

\subsection{Microstructure and Mechanical Properties of the Cold Rolled and Annealed Samples}

In coil $A \& B$, equiaxed ferrite grains are present in both coil center and edge in the cold rolled and annealed
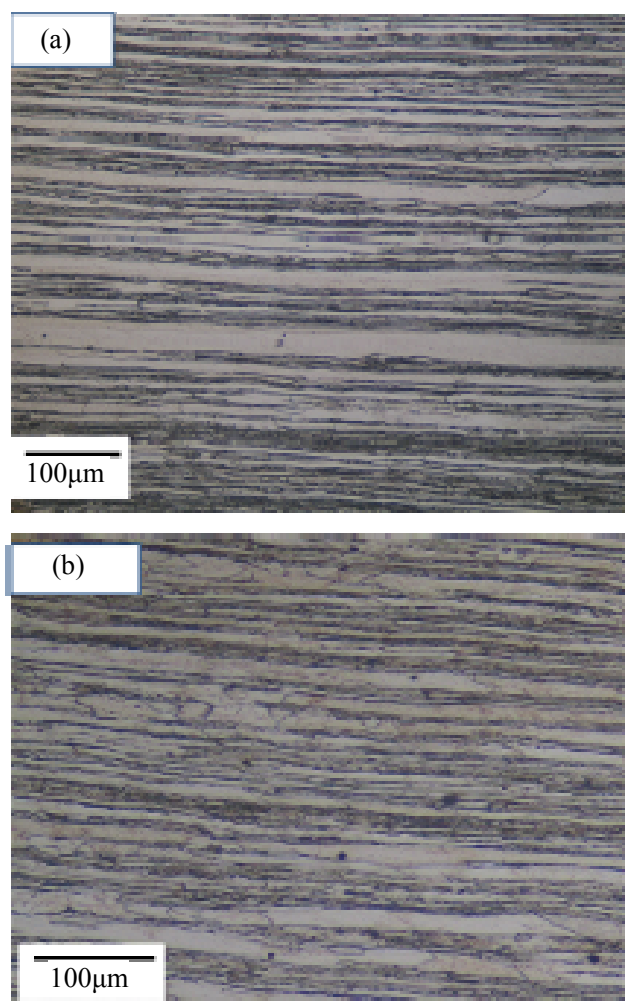

Figure 5. (a) Microstructure of coil $\mathbf{C}$ just after hood annealing, (b) Microstructure after $33 \%$ cold reduction and subsequent annealing of hood annealed coil $D$. 

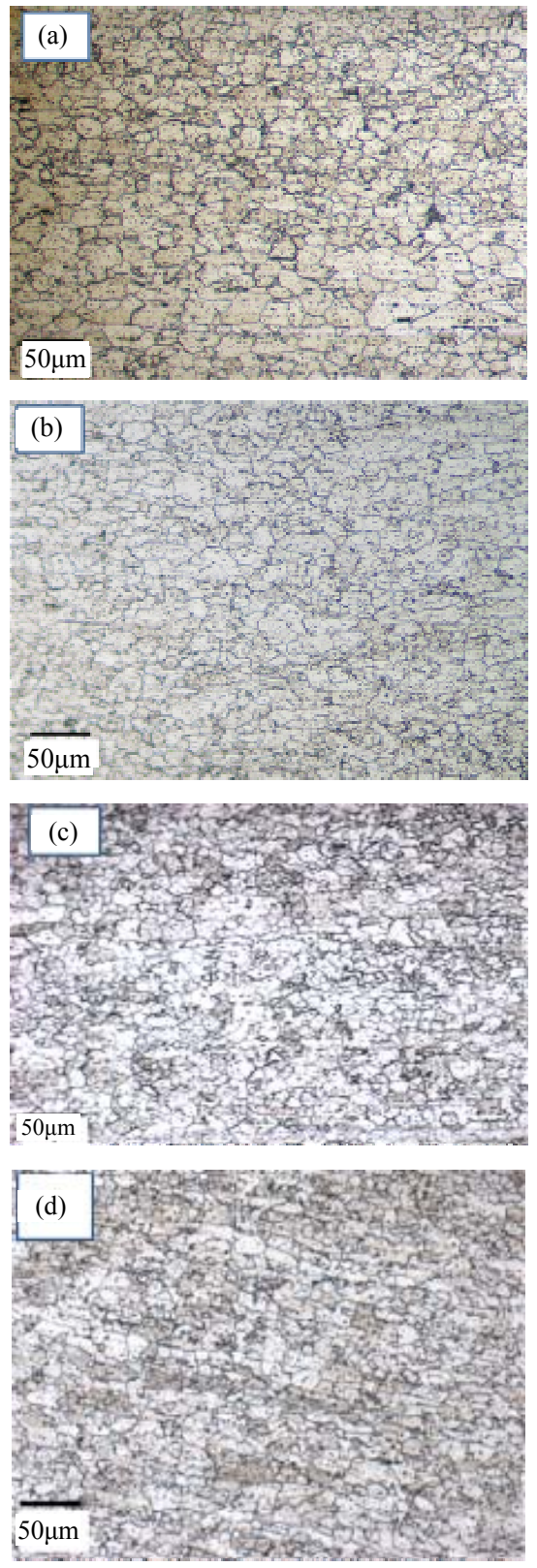

Figure 6. Microstructure of cold rolled and annealed sample of (a) coil A center (b) coil A edge (c) Coil B center (d) Coil $B$ edge.

recondition (Figure 6). Recrystallized grains of ASTM 8.5 to 9 (Table 2) were observed in the center samples of the coils whereas coil end samples are slightly finer (ASTM 9 - 9.5) in size.

In the hood annealed coils, while recrystallization occurred after cold rolling and annealing, the grains are pancake shaped (Figure 7). The grains are also slightly finer in size as shown in Table 2. Occurrence of deformation in the presence of martensite can be the reason of finer grains in hood annealed coils.

Due to decrease in the grain size, increase in the yield strength and marginal decrease in the ductility can be observed (Table 2) in the hood annealed coils.

\subsection{Texture of the Cold Rolled and Annealed Coils}

Figure 8 shows $\varphi_{2}=45^{\circ}$ section of the ODF measured in the cold rolled and annealed coils. A weak $<111>$
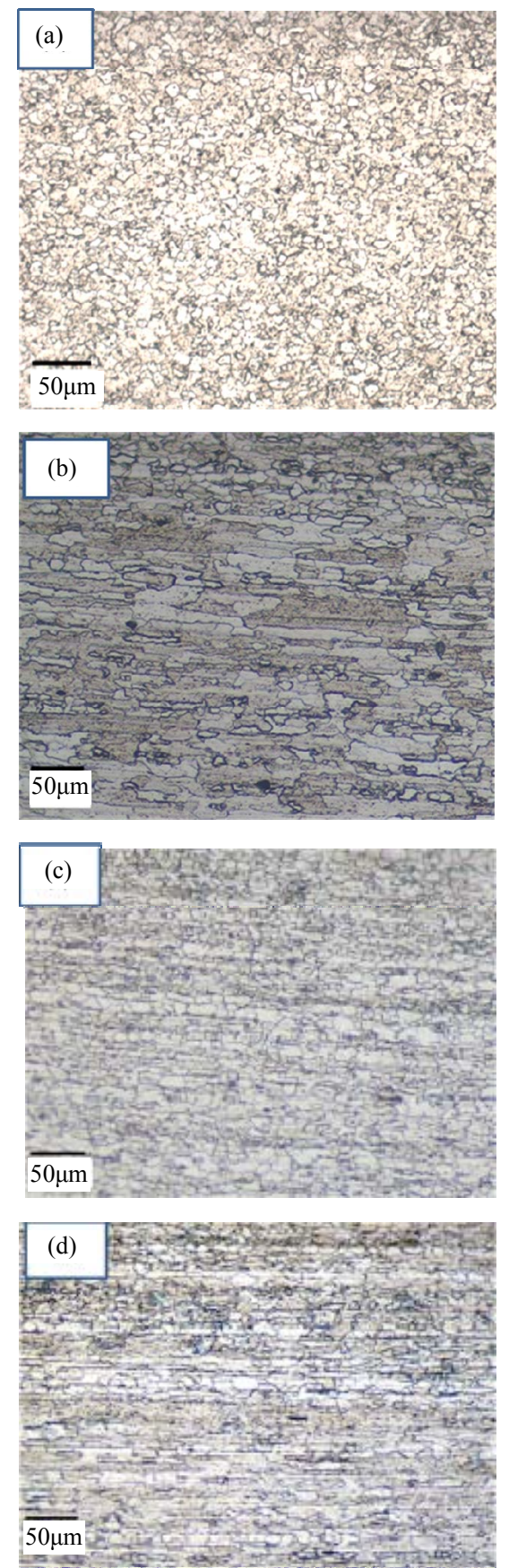

Figure 7. Microstructure of cold rolled and annealed samples of hood annealed coils (a) coil $C$ center, (b) coil $C$, end (c) coil $D$ center and (d) coil $D$ end. 
Table 2. Mechanical properties of the cold rolled and annealed coils in $0.6 \mathrm{~mm}$ thickness.

\begin{tabular}{ccccccc}
\hline Coils & $\begin{array}{c}\text { Yield Strength } \\
(\mathrm{MPa})\end{array}$ & $\begin{array}{c}\text { Tensile Strength } \\
(\mathrm{MPa})\end{array}$ & $\begin{array}{c}\text { \%Fracture } \\
\text { Elongation }\end{array}$ & $\begin{array}{c}\text { Cupping } \\
\text { Value (mm) }\end{array}$ & Grain Size (ASTM No.) & Hardness (HV) \\
\hline Coil A-center & 317 & 503 & 29 & 9.7 & 8.5 & 153 \\
Coil B-center & 335 & 526 & 27 & 9.5 & 9 & 158 \\
Coil C-center & 356 & 575 & 24 & 8.4 & 10.5 & 167 \\
Coil D-center & 347 & 554 & 25 & 8.8 & 9.5 & 162 \\
Coil A edge & 324 & 495 & 29 & 9.5 & 9.5 & 155 \\
Coil B edge & 345 & 521 & 26 & 9.4 & 10.5 & 159 \\
Coil C edge & 363 & 581 & 24 & 8.3 & 10 & 169 \\
Coil D edge & 352 & 543 & 24 & 8.9 & 160 \\
\hline
\end{tabular}
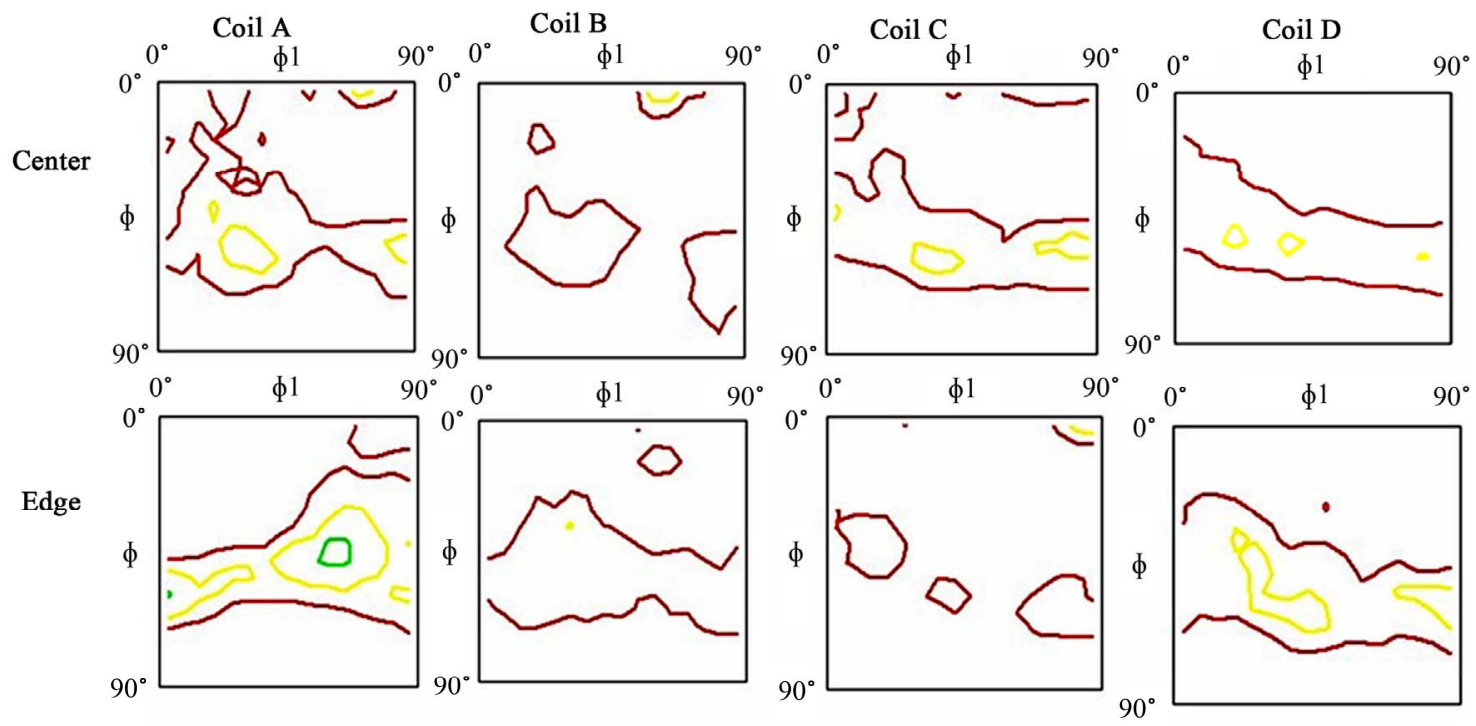

Figure 8. ODF from the center and edge sample of Coil A, Coil B, Coil C, Coil D respectively.

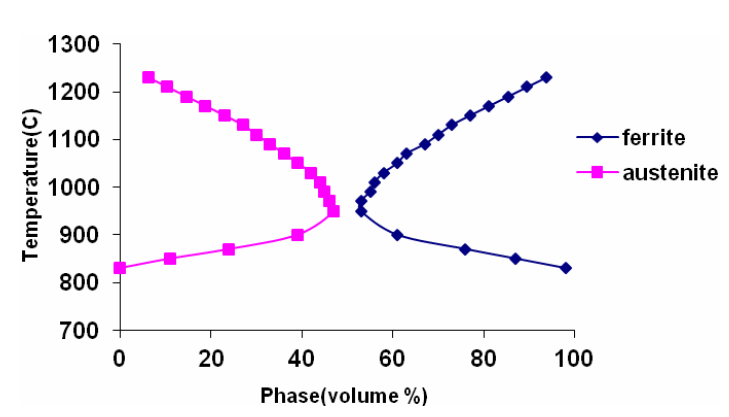

Figure 9. Equilibrium austenite volume fraction present in different temperature calculated.

crystallization texture is observed in all four coils. In all three single stage cold rolled coils A, B and C, $\{001\}$ $<\mathrm{uv} 0>$ component is observed which is absent in coil D which has undergone two stage cold rolling. The $\{001\}$ $<\mathrm{uv} 0>$ component was absent in this coil in both center and coil edge samples. This appears to be on account of reduction of texture gradient due to intermediate annealing during cold rolling as noted by Huh and Engler [6].

\subsection{Correlation of Ridging and Microtexture Result}

Equilibrium austenite fraction of the steel composition by Thermocalc software is given in Figure 9 and austenite continuously increases from $1230^{\circ} \mathrm{C}$ to $950^{\circ} \mathrm{C}$ and then it decreases down to $830^{\circ} \mathrm{C}$. For Coil A which is soaked at $1170^{\circ} \mathrm{C}$, equilibrium austenite fraction at slab soaking temperature is about 24 percent. Coil B, C, D were soaked at $1210^{\circ} \mathrm{C}$ and austenite fraction is about 8 percent at that 
temperature. As coil A and coil B had similar processing schedule and only difference is soaking temperature, better ridging resistance in coil $\mathrm{B}$ can be explained by the higher soaking temperature. Mola et al. [9] suggested that low $\gamma$ phase fraction at soaking temperature and thus nucleation of large fraction of $\gamma$ phase in the $\alpha$ phase is beneficial for ridging resistance. Thus high soaking temperature has beneficial effect on ridging resistance. The $\gamma$ phase on cooling converts to martensite. Hamada et al. [11] observed that the presence of martensite can randomize the banded structure effectively to reduce anisotropy. Presence of martensite distributed uniformmly in the microstructure can be a very effective way to minimize ridging height.

EBSD micro texture maps of central portion of all the coils are shown in both RD and ND direction of the samples in Figures 10 and 11. Texture colonies were hardly seen in the ND map. In the RD map of coil A, centre region sample contains some of the $<001>$ colonies (red colour) which can be correlated to slightly higher ridging observed in this coil. In the coils B, C and D, <001> colonies are not observed in these coils (Figure 10). In our study, coil end samples are free from any type of grain colonies (Figure 12) and grain size is smaller (Table 2) than the center sample. Such freedom from grain colonies coupled with finer grain size appears to be the reason for higher ridging resistance of the coil end samples.

\section{Conclusions}

Four differently processed coils were studied by varying the annealing, cold rolling and soaking temperature. The following conclusions were arrived.
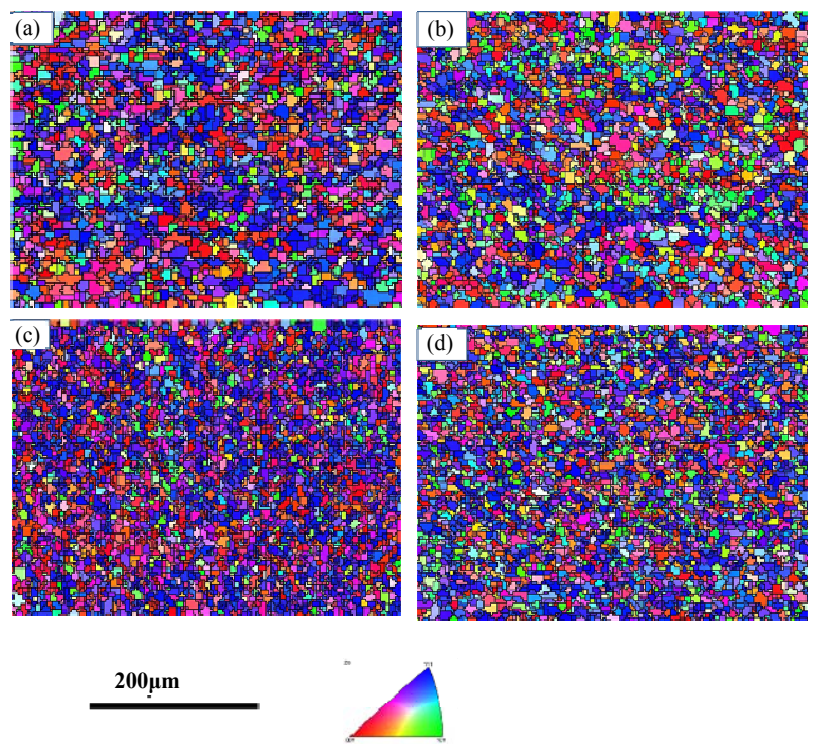

Figure 10. IPF map of the ND of specimen (a) Coil A (b) Coil B(c) Coil C and (d) Coil D.

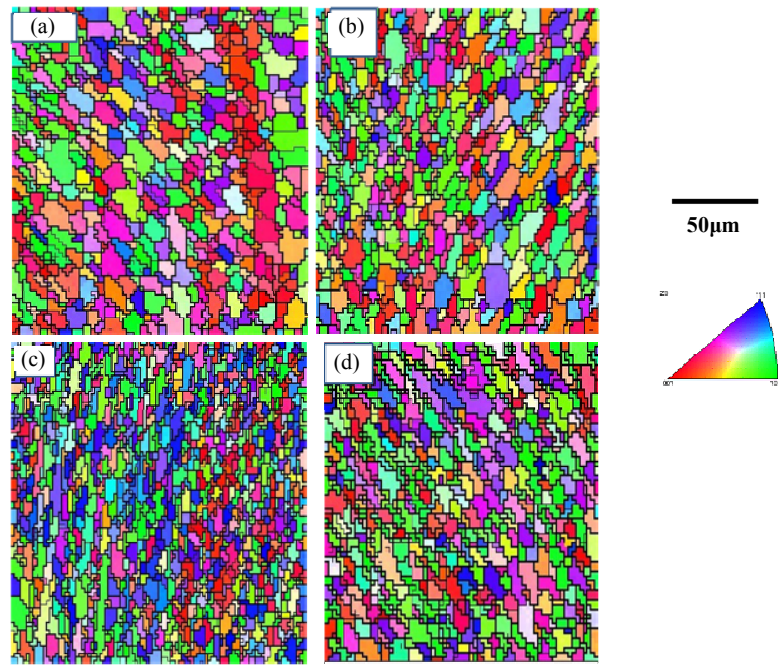

Figure 11. IPF map of RD of specimen (a) Coil A, (b) Coil B, (c) Coil C, (d) Coil D respectively.
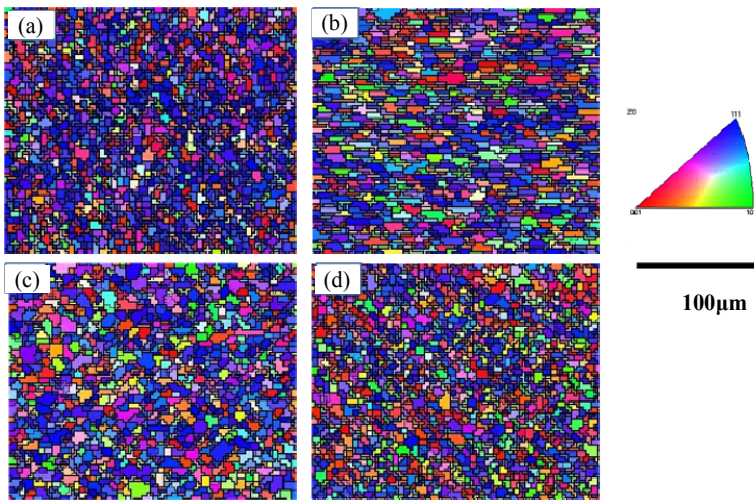

$100 \mu \mathrm{m}$

Figure 12. IPF map of the ND of end of (a) Coil A (b) Coil B(c) Coil C (d) Coil D.

1) Smaller austenite fraction at the ingot soaking temperature coupled with copious precipitation during hot rolling is very beneficial for ridging resistance.

2) Hood annealing route can produce better ridging resistance than batch annealing route by randomization of the colony structure by rolling of dual phase structure.

3) On account of relatively coarser grain size and lower yield strength, the ductility and stretch formability of batch annealed coils are marginally better.

4) Due to slightly smaller grain size in the end of the coils ridging resistance is higher than coil centre.

\section{Acknowledgements}

Authors are grateful to K. V. Narashima Rao from JSL, Hisar for his valuable support during the work.

\section{REFERENCES}

[1] R. N. Wright, "Anisotropic Plastic Flow in Ferritic Stainless 
Steels and the Roping Phenomenon," Metallurgical and Materials Transactions, Vol. 3, No. 1, 1967, pp. 83-91. doi:10.1007/BF02680588

[2] H. J. Shin, J. K. An, S. H. Park and D. N. Lee, "The Effect of Texture on Ridging of Ferritic Stainless Steel," Acta Materialia, Vol. 51, No. 16, 2003, pp. 693-706. doi:10.1016/S1359-6454(03)00187-3

[3] J. C. Kim, J. J. Kim, J. Y. Choi, J. H. Choi and S. K. Kim, "Control of Columnar to Equiaxed Transition in Continuous Casting of $16 \%$ Cr Stainless Steel," European Conference Continuous Casting of Steel, Riccione, 3-6 June 2008.

[4] K. Kimura, T. takeshita, A. Yamamoto and J. Harase, "Hot Recrystallization Behavior of SUS 430 Stainless Steel," Nippon Steel Technical Report, No. 71, 1996.

[5] B. K. Jha, P. Jha and C. D. Singh, "Processing Technology for the Continuous Hot Band Annealing of $17 \% \mathrm{Cr}$ Ferritic Stainless Steel," Journal of Materials Engineering and Performance, Vol. 11, No. 2, 2002, pp. 180-186. doi:10.1361/105994902770344240

[6] M. huh, J. H. Lee, S. H. Park, O. Engler and D. Raabe, "Effect of through Thickness Macro and Micro-Texture Gradients on Ridging of $17 \%$ Cr Ferritic Stainless Steel Sheet," Steel Reasearch Int., Vol. 76, No. 11, 2005, pp.
797-806.

[7] M. Y. Huh and O. Engler, "Effect of Intermediate Annealing on Texture, Formability and Ridging of $17 \% \mathrm{Cr}$ Ferritic Stainless Steel," Materials Science and Engineering: $A$, Vol. 308, No. 1-2, 2001, pp. 74-87. doi:10.1016/S0921-5093(00)01995-X

[8] J. Avila and M. Zapata, "Recrystallization Behavior of Cold Rolled Dual Phase Ferritic stainless Steels and Its Effect on Formability," Stainless Steel World, 2004, pp. $1-7$.

[9] J. Mola, I. Jung, J. Park, D. Chae and B. C. De Cooman, "Ridging Control in Transformable Ferritic Stainless Steel," Metallurgical and Materials Transactions A, Vol. 43, No. 1, 2012, pp. 228-243. doi:10.1007/s11661-011-0824-7

[10] D. Wei, J. L. Zhu, S. Quan-She, L. Zhen-Yu and Z. Xin, "Effect of Hot Band Annealing Process on Microstructure, Texture and R-Value of Ferritic Stainless Steel," Journal of Iron and Steel Research, Vol. 17, No. 7, 2010, pp. 5862.

[11] J. Hamada, Y. Matsumoto, F. Fudanoki and S. Maeda, "Effect of Initial Solidified Structure on Ridging Phenomenon and Texture in Type 430 Stainless Steel Sheets," ISIJ International, Vol. 43, No. 12, 2003, pp. 1989-1998. 